\title{
SCIENTIFIC CORRESPONDENCE
}

\section{Periorbital dermatitis as a side effect of topical dorzolamide}

\author{
Y M Delaney, J F Salmon, F Mossa, B Gee, K Beehne, S Powell
}

Br J Ophthalmol 2002;86:378-380

Aim: To report periorbital dermatitis as a late side effect of topical dorzolamide hydrochloride (Trusopt), a drug used to reduce intraocular pressure.

Methods: A retrospective study of 14 patients who developed periorbital dermatitis while using topical dorzolamide hydrochloride was undertaken. Six patients underwent patch testing for sensitivity to Trusopt, dorzolamide hydrochloride, and the preservative benzalkonium chloride.

Results: The periorbital dermatitis occurred after a mean period of 20.4 weeks of commencing dorzolamide hydrochloride therapy. 13 patients had used preserved topical $\beta$ blocker treatment for a mean period of 34.2 months without complication before the introduction of dorzolamide. In eight $(57.1 \%)$ the dermatitis resolved completely after discontinuing dorzolamide but in six $(42.9 \%)$ resolution of the dermatitis did not occur until the concomitant preserved $\beta$ blocker was stopped and substituted with preservative free drops. Patch testing for sensitivity to Trusopt, dorzolamide hydrochloride, and benzalkonium chloride was negative. Conclusion: These findings suggest that dorzolamide can cause severe periorbital dermatitis. Although the dermatitis may resolve when dorzolamide is discontinued, this does not always occur and in some patients all topical medication containing benzalkonium chloride needs to be stopped.

$\mathrm{T}$ opical dorzolamide hydrochloride (Trusopt; Merck \& Co Inc, West Point, PA, USA) is a thienothio-pyran-2sulphonamide carbonic anhydrase inhibitor. ${ }^{1}$ It is formulated as an aqueous solution using standard ophthalmic components, including hydroxyethyl cellulose, and preserved with $0.0075 \%$ benzalkonium chloride. Compared to oral carbonic anhydrase inhibitors (CAI) a significantly lower incidence of systemic side effects occurs with topical application. However, local side effects such as stinging, tearing, blurred vision, photophobia, conjunctivitis, punctate epithelial keratitis, and corneal decompensation have been reported. ${ }^{2}$

In this study, we present a series of 14 patients who developed moderate to severe periorbital dermatitis as a late side effect of topical dorzolamide. To our knowledge, only one previous case of this complication has been published. ${ }^{3}$

\section{METHODS}

Between 1996 and 1998, 14 patients who developed periorbital dermatitis while on dorzolamide hydrochloride presented to the Oxford Eye Hospital (Figs 1 and 2). We retrospectively reviewed their clinical and photographic records. Age, sex, ophthalmic diagnosis, history, duration of topical medications, and history of previous allergy were recorded. Statistical analysis was undertaken using Fisher's exact test and a p value of $<0.05$ was considered statistically significant.

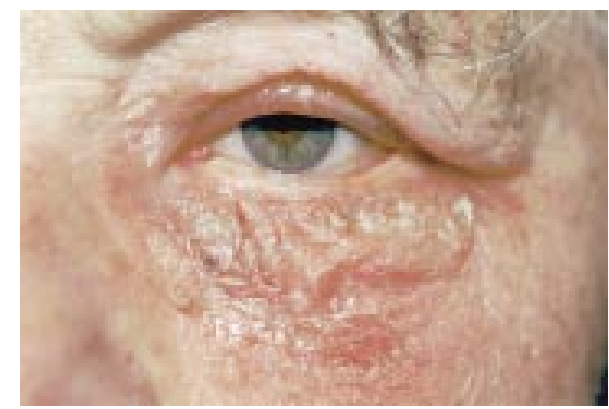

Figure 1 Case 14. Marked dermatitis of the left lower lid and periorbital area, which resolved on discontinuing topical dorzolamide.

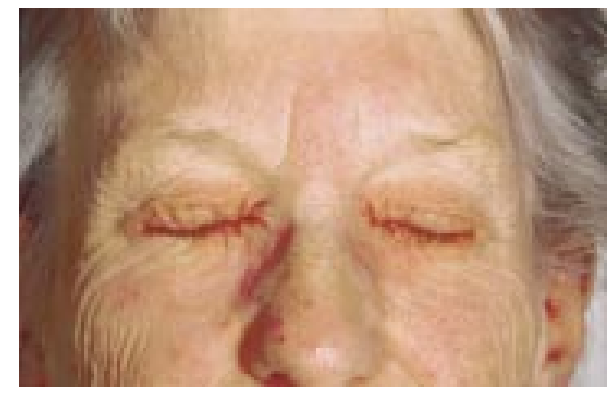

Figure 2 Case 2. Bilateral periorbital dermatitis with erythema and scaling involving the upper and lower lids.

All patients were contacted by letter to attend for patch testing at the dermatology department of the Churchill Hospital, Oxford and six patients accepted (see Table 1). Patch testing was carried out according to the International Contact Dermatitis Research Group (ICDRG) recommendations and was performed on average 16 months (range 5-43 months) after the dermatitis occurred. Using the Finn chamber method, six patients were tested to a standard series of allergens, to benzalkonium chloride $0.1 \%$ in water, to Trusopt, and to pure dorzolamide hydrochloride $1 \%$, both in petrolatum and water. The duration of occlusion was 2 days and results were read at day 3 and day 5 . These patients were also prick tested to Trusopt and results read at 15 minutes and 48 hours. Three patients later underwent patch testing to dorzolamide hydrochloride 5\% applying one series to normal skin and another series to cellotape stripped skin, to aid penetration of dorzolamide through the epidermis.

\section{RESULTS}

The clinical findings of the 14 patients are summarised in Table 1.

All 14 patients developed dermatitis while using topical dorzolamide treatment. This occurred a mean period of 20.4 weeks (range 4-40 weeks) after commencing therapy. At the 
Table 1 Summary of ophthalmic diagnosis, duration and type of glaucoma medications, and history of previous allergy

\begin{tabular}{|c|c|c|c|c|c|c|}
\hline Patient No & Age, sex & Diagnosis & $\begin{array}{l}\text { Concomitant topical bb } \\
\text { and duration of Rx } \\
\text { (months) } \dagger\end{array}$ & $\begin{array}{l}\text { Duration of Trusopt } \\
\operatorname{Rx} \text { (weeks) }\end{array}$ & $\begin{array}{l}\text { Resolution after } \\
\text { withdrawal of } \\
\text { Trusopt }\end{array}$ & $\begin{array}{l}\text { Previous adverse reaction } \\
\text { to topical medication }\end{array}$ \\
\hline 1 & $77, M$ & POAG & Levobunolol (33) & 20 & No & None \\
\hline 2 & $84, \mathrm{~F}$ & POAG & Betaxolol (12) & 20 & Yes & Neomycin \\
\hline 3 & $75, \mathrm{~F}$ & $\mathrm{HZO}$ & Betaxolol (83) & 28 & Yes & Dipivefrin \\
\hline 4 & $87, \mathrm{~F}$ & PXF & Levobunolol (33) & 8 & No & Dipivefrin \\
\hline 5 & $74, M^{*}$ & POAG & Timolol (58) & 8 & No & Chloramphenicol \\
\hline 6 & $73, F$ & POAG & Levobunolol (30) & 36 & Yes & None \\
\hline 7 & $66, M^{*}$ & $\mathrm{OHT}$ & Betaxolol (32) & 24 & Yes & Dipivefrin \\
\hline 8 & $83, F$ & POAG & Timolol (49) & 24 & Yes & None \\
\hline 9 & $75, M^{*}$ & POAG & Timolol (45) & 40 & No & Dipivefrin \\
\hline 10 & $82, F^{*}$ & POAG & Levobunolol (12) & 9 & Yes & None \\
\hline 11 & $87, M$ & $\mathrm{OHT}$ & None & 4 & Yes & None \\
\hline 12 & $58, M$ & $\mathrm{OHT}$ & Timolol (24) & 24 & No & Dipivefrin \\
\hline 13 & $66, M^{*}$ & POAG & Levobunolol (19) & 20 & No & None \\
\hline 14 & $65, M^{*}$ & POAG & Levobunolol (15) & 20 & Yes & None \\
\hline
\end{tabular}

$\mathrm{POAG}=$ primary open angle glaucoma, $\mathrm{HZO}=$ herpes zoster ophthalmia, $\mathrm{PXF}=$ pseudoexfoliation, $\mathrm{OHT}=$ ocular hypertension, $\mathrm{Rx}=$ treatment, $\mathrm{bb}=\beta$ blocker.

*Patients who underwent patch testing; the time recorded is the duration of $\beta$ blocker therapy before the introduction of dorzolamide.

time of presentation 13 patients were on dual topical therapy and one patient was using topical dorzolamide as monotherapy. All patients on dual therapy had used preserved topical $\beta$ blocker treatment (levobunolol six, timolol four, betaxolol three) before the introduction of dorzolamide drops for a mean period of 34.2 months (range 12-83 months) without complication. Following the appearance of dermatitis, dorzolamide was discontinued in all patients. The average time interval between onset of symptoms and withdrawal of dorzolamide was 4 weeks (range 1-9 weeks).

In eight patients (group 1), the dermatitis resolved following withdrawal of topical dorzolamide. Adequate intraocular pressure control was maintained by using other preserved glaucoma medication. In the remaining six patients (group 2), the dermatitis did not resolve until the concomitant topical $\beta$ blocker (levobunolol three, timolol three) was stopped and replaced by the preservative free equivalent drug. The patients in group 2 had experienced no side effects to topical $\beta$ blocker therapy for a mean period of 28.3 months (levobunolol) and 42.3 months (timolol) respectively, before the introduction of topical dorzolamide. Overall, seven patients had a history of adverse reactions to other topical medications (dipivefrin five, neomycin one, chloramphenicol one), occurring more frequently in group 2 at $66.6 \%$ versus $37.5 \%$ for group 1, but this did not reach statistical significance $(\mathrm{p}=0.2)$.

Following resolution of their dermatitis 12 patients declined to be clinically rechallenged with topical Trusopt. In the two patients who accepted, there was recurrence of eyelid dermatitis within 4 days of recommencing Trusopt. Four patients from group 2 were rechallenged with topical medication that included benzalkonium chloride on average 26 months (range 22-32 months) after resolution of their dermatitis. No adverse conjunctival or lid hypersensitivity occurred and these patients are now maintained on preserved monotherapy $(n=2)$ or preserved dual therapy $(n=2)$ without complication.

Patch testing was negative in all six patients.

\section{DISCUSSION}

Carbonic anhydrase inhibitors are related to the sulphonamide group of drugs which are known sensitisers, ${ }^{3}$ and ocular hypersensitivity reactions have been reported with dorzolamide which include conjunctivitis, eyelid oedema, and eyelid irritation. ${ }^{4-6}$ Our literature search revealed only one previous report of allergic dermatitis caused by Trusopt. ${ }^{3}$ The case described shares clinical similarities with our cases, with the dermatitis occurring late (after 1 year of treatment) and only improving after concomitant topical timolol was substituted with a preservative free preparation.
In this series, the dermatitis occurred a mean period of 20.4 weeks (range 4-40 weeks) after commencing therapy with topical dorzolamide. Patients obtained their medication from different pharmacies throughout the Oxfordshire area, over an average period of 5 months, which discounts the possibility of a manufacturing error isolated to one particular batch of Trusopt as the cause of the dermatitis in these patients.

In our unit dorzolamide is most often used as an adjuvant rather than as a primary therapy and 13 of the 14 patients had been on topical $\beta$ blocker therapy for a mean period of 34.2 months without complication before dorzolamide was introduced. Topical $\beta$ blockers have been used as first line hypotensive therapy in the medical management of glaucoma for more than 30 years and an extensive local side effect profile has been documented which includes blurring, irritation, corneal anaesthesia, and punctate keratitis. ${ }^{7}$ However, contact dermatitis is rarely associated with their use and in our literature search, using the Medline database, we found a total of 15 case reports of patients who developed contact allergy to topical timolol, ${ }^{8-12}$ levobunolol, ${ }^{11-16}$ or betaxolol therapy. ${ }^{17}$ Furthermore, the continued tolerance of topical $\beta$ blocker therapy by both groups (with their original $\beta$ blocker in group 1 and with the identical $\beta$ blocker, but in a preservative free form in group 2 ) excludes any causative role of this medication in the development of dermatitis in these patients.

Analysis of our cases suggests that the long term outcome of dorzolamide induced dermatitis can be divided into two groups: those that resolve on stopping topical dorzolamide (group 1) and those that only resolve on stopping all topical medications that include preservatives in their formulation (group 2). Resolution of the dermatitis following withdrawal of both dorzolamide and preserved $\beta$ blocker suggests sensitivity to repetitive contact with their common preservative, benzalkonium chloride, as the responsible mechanism. However, it is unlikely that benzalkonium chloride was the primary causative agent as these patients had received preserved $\beta$ blocker therapy without complication for a mean of 28.3 months (levobunolol) and 42.3 months (timolol), respectively, before the introduction of topical dorzolamide. Once complete resolution had occurred (22-32 months later) four out of six patients in group 2 were rechallenged with topical benzalkonium chloride and no adverse conjunctival or lid hypersensitivity reactions were recorded. Interestingly, Aalto-Korte et al documented a similar finding in their case report. ${ }^{3}$ This fact has important implications, as it allows resumption of treatment in time, from the full range of glaucoma medications.

In our patients who underwent patch testing, no skin reaction was found on testing to Trusopt, benzalkonium chloride, 
and dorzolamide hydrochloride $1 \%$ and $5 \%$. In the previously reported case of allergic dermatitis caused by dorzolamide, strongly positive skin reactions to dorzolamide, down to a dilution of $0.5 \%$ aqueous and $1 \%$ petrolatum were recorded, thereby confirming a true contact allergy. ${ }^{3}$ Our methodology was identical to that used by Aalto-Korte and the reason for the repeatedly negative patch testing in our patients is not clear. False negative results following patch tests to commercial ophthalmic solutions are not infrequent and have been reported in the literature. ${ }^{11}$ Herbst et al, ${ }^{18}$ in a review of the subject, also reported cases of allergic dermatitis caused by topical ophthalmic preparations which defied aetiological diagnosis, either because they represented false negative patch tests, or because irritation, rather than sensitisation, was involved. Some authors have therefore modified their technique by performing patch testing on stripped skin (as we did in three of our patients) or by increasing the size of the patch test area. ${ }^{12} 19$ Interestingly, in the two patients who were rechallenged with topical dorzolamide, the periorbital dermatitis recurred within 4 days, thus satisfying one of the criteria proposed by Naranjo et al to assess causality of adverse events by drugs. ${ }^{20}$

In conclusion, this retrospective study suggests that dorzolamide can cause severe periorbital dermatitis in patients with glaucoma or ocular hypertension. While the dermatitis resolves after withdrawal of dorzolamide in most patients, in others a subsequent irritation to the preservative benzalkonium chloride occurs. Patients on dorzolamide should be warned of this potential late side effect.

\section{Authors' affiliations \\ M Delaney, J F Salmon, F Mossa, Department of Ophthalmology, John Radcliffe Hospitals NHS Trust, Oxford, OX2 6HE, UK \\ B Gee, K Beehne, S Powell, Department of Dermatology}

Correspondence to: Mr J F Salmon, Oxford Eye Hospital, Radcliffe Infirmary, Woodstock Road, Oxford OX2 6HE, UK;

john.salmon@orh.nhs.uk

Accepted for publication 10 October 2001

\section{REFERENCES}

1 Pfeiffer N. Dorzolamide: development and clinical application of a topical carbonic anhydrase inhibitor. Surv Ophthalmol 1997:42:137-51

2 Konowal A, Morrison J, Brown S, et al. Irreversible corneal decompensation in patients treated with topical dorzolamide. Am J Ophthalmol 1999;127:403-6.

3 Aalto-Korte K. Contact allergy to dorzolamide eyedrops. Contact Dermatitis 1998;39:206

4 Wilkerson M, Cyrlin M, Lippa E, et al. Four week safety and efficacy study of dorzolamide, a novel, active topical carbonic anhydrase inhibitor. Arch Ophthalmol 1993;111:1343-50.

5 Strahlman E, Tipping R, Vogel R, and the International Dorzolamide Study Group. A double-masked, randomized, 1-year study comparing dorzolamide (Trusopt), timolol and betaxolol. Arch Ophthalmol 1995;1 13:1009-16.

6 Hartenbaum D. The efficacy of dorzolamide, a topical carbonic anhydrase inhibitor, in combination with timolol in the treatment of patients with open angle glaucoma and ocular hypertension. Clin Ther 1996;18:460-5.

7 Cantor L, Berlin M, Hodcapp E, et al. Glaucoma. In: Section 10, Basic and clinical science course: San Francisco: American Academy of Ophthalmology, 1997:105-8.

8 Cameli N, Vicenzi C, Tosti A. Allergic contact conjunctivitis due to timolol in eyedrops. Contact Dermatitis 1991;25:129-30.

9 Fernandez-Vozmediano J, Blaisi N, Romero-Cabrera M, et al. Allergic contact dermatitis to timolol. Contact Dermatitis 1986;14:252.

10 Romaguera C, Grimalt F, Vilaplana J. Contact dermatitis by timolol. Contact Dermatitis 1986;14:248

11 De Groot A, van Ginkel CJ, Bruynzeel DP, et al. Contact allergy to eyedrops containing beta-blockers. Nederslands Tijdschrift voor Geneeskunde 1998;142:1034-6.

12 Koch P. Allergic contact dermatitis due to timolol and levobonolol in eyedrops, ith no cross-sensitization to other ophthalmic beta-blockers. Contact Dermatitis 1995;33:140-1

13 Di Lernia V, Albertini G, Bisighini G. Allergic contact dermatitis from levobunolol eyedrops. Contact Dermatitis 1995;33:57

14 Garcia F, Blanco J, Juste S, et al. Contact dermatitis due to levobunolol in eyedrops. Contact Dermatitis 1997;36:230.

15 Zucchelli V, Silvani S, Vezzani C, et al. Contact dermatitis from levobunolol and befunolol. Contact Dermatitis 1995;33:66-7.

16 Erdmann S, Hertl M, Merk H. Contact dermatitis from levobunolol eyedrops. Contact Dermatitis 1999:41: 44-6.

17 O'Donnell B, Foulds I. Contact allergy to beta-blocking agents in ophthalmic preparations. Contact Dermatitis 1993;28:121-2.

18 Herbst R, Maibach H. Allergic contact dermatitis from ophthalmics: update 1997. Contact Dermatitis 1997;37:252-3.

19 Gailhoper G, Ludvan M. 'Beta-blockers': sensitizers in periorbital allergic contact dermatitis. Contact Dermatitis 1990;23:262.

20 Naranjo CA, Busto U, Sellers EM, et al. A method for estimating the probability of adverse drug reactions. Clin Pharm Ther $1981 ; 30: 239-45$.

\section{Contributors please note:}

Communications from all countries except the UK and Republic of Ireland should be sent to Professor C Hoyt, Editor, British Journal of Ophthalmology, University of California, Department of Ophthalmology, 10 Kirkham Street, K 301, San Francisco, CA 94143-0730, USA (tel: 001415502 6871; fax: 001415514 1521).

Manuscripts from the UK and the Republic of Ireland should be sent to Professor Andrew Dick, UK Editor, British Journal of Ophthalmology, Division of Ophthalmology, Unversity of Bristol, Lower Maudlin Street, Bristol BS1 2LX (tel: +44 (0) 117929 4496; fax: +44 (0) 117929 4607). 